\title{
Implications of Global Financial Crisis on Textile Industry of Pakistan
}

\author{
Sumra Latif Mughal \\ Mehrunissa Chaudhary \\ MS Scholar at UET Lahore
}

Shaheed Zulfikar Ali Bhutto Institute of Science and Technology (SZABIST

\begin{abstract}
The global financial crisis of 2008, had very little or no impact on our textile sector performance, the main cause of downward trend of Pakistan textile industry is the reason of energy shortages, law and order situation, lack of active marketing strategies, and the behavior or small, medium and large manufacturers of textile products are more profit oriented, ignoring their responsibility towards social and economic development of Pakistan. The author purpose was to explore the phenomenon of financial crisis and the performance of Pakistan industry how they are linked and what factors were linked with both the crisis. The phenomenon studied includes the era of financial crisis and simultaneously the crisis of textile industry of Pakistan and to identify the weak links. This study also aims to analyze the potential of productivity and investment of textile sector and its contribution in the earnings for the Government of Pakistan. The research participants were from the area of field research on textile sector of Pakistan, working on it since last 4 to 5 years. Data analysis was done by using Colaizzi's (1978) phenomenological methods; was used for data analysis, validation and verification. Out of various statements 12 themes emerged which represents the whole story how the textile sector crisis took place and the factors behind them.
\end{abstract}

Key words: Financial Crisis, Textile Sector, Raw Cotton, Phenomenological study

\section{Introduction:}

The Global Financial Crisis started on October 2008, which created two perceptions on its likely impact on the developing Asian countries; on one hand it was perceived that developing Asia, particularly China and some other countries, are now decoupled with the developed countries and would emerge as an alternative growth poles. The other school of thought believed that because of Globalization, this region has more dependence on trade and investment and mainly on exports; it was likely that this region would be highly affected by the crisis. However a mix outcome has been witnessed by the world, it does not resulted in decline of GDP but the growth of these countries have slowed (Chhibber J, Ghosh J, Palanivel T 2009).

The impact of financial crisis is not similar in all countries around the world, depending upon the level of difference between reliance on exports and positions within globalization. The 'inner critical core' (Green D, King R, Dawkins M 2010) countries namely China, Vietnam and Indonesia - has consolidated its production of textiles and garments into a pool of strategic suppliers'. The customers mainly rely for the most important share of their production, during 'Bad times' their orders may fall but their market share remain intact, in contrast to second line suppliers e.g. India, Pakistan, and Sri Lanka nad marginal suppliers like Caribbean Basin and Cambodia, which experience drops in both order and market share (Green D, King R, Dawkins M 2010).

The Textile and garments industry is one of the most globalized sectors of the world providing employment opportunities to more than 60 million people around the world (Forstater M 2007). Textile industry of Pakistan contributes almost $60 \%$ (USD 9.6 Billion) to the countries total exports and $46 \%$ to the total output i.e. $8.5 \%$ to the country's GDP. Among Asian countries Pakistan is the $8^{\text {th }}$ largest producer of textile products and contributing $38 \%$ to the total employment of the country, but its contribution in the international textile market is very marginal as compare to the neighboring countries. China, India, Bangladesh, Vietnam and Indonesia are highly mechanized and equipped with technology to produce high quality, low priced textile products and increased supply in international market (Tahir M, Mughal K 2012).

The Global Financial crisis affected these countries minimally but its impact on Pakistan is more severe, contributing to the decline of textile industry other factors included law and order situation, Electricity and gas shortages, inflation, Political instability and stock exchange volatility etc. all resulted in movement of our industry to Bangladesh and other countries. The main aim of this study is to identify how factors associated with financial crisis impacting the textile industry of Pakistan, mainly from the point of view of experts who are religiously following the pre and post crisis period.

The purpose of this study is to discover and know the situation of Textile sector of Pakistan through obtaining the information from key participants in their respective area of knowledge and understanding of the phenomena under study. What they had experienced during the crisis and how they reacted to the situation, what steps they have been taking in order to improve the textile sectors performance. The experiences of people from the textile sector during the crucial period will allow us to have insights of the actual situation which prevailed at that point of time. 
The main aim of this study is to identify how factors associated with global financial crisis of 2008 had an impact on the textile sector of Pakistan. The phenomena that will be studied will include the era of financial crisis and simultaneously the crisis of textile industry of Pakistan and to identify the weak links. This study also aims to analyze the potential of productivity and investment of textile sector and its contribution in the earnings for the Government of Pakistan.

\section{Literature Review:}

Pakistan is the $8^{\text {th }}$ largest producer of textile products and $4^{\text {th }}$ largest producer of cotton in Asia, competing with China, India and Bangladesh as major rivals in the International Market. The Financial Crisis of 2008 has also affected the Developing Asia (Green D, King R, Dawkins M 2010), the inner circle including countries like China, Vietnam and Indonesia which were directly exporting value added products to United States and EU were more severely affected than those of outer circle countries namely, Pakistan, India and Bangladesh. Pakistan is the major exporter of raw material to the regional textile producing countries namely China, India and Bangladesh, therefore the impact of financial crisis is not severe in Pakistan as compare to those countries who are direct exporters of finished goods to the countries where the bubble burst. Textile sector of Pakistan is assumed to be the backbone of the economy, its contribution in the GDP is $8.5 \%$, employing almost $30 \%$ of the country's population of around 15 million people. \$ 18 trillion is the annual volume of total world textile trade, which is growing at the rate of $2.5 \%$ per year, but contribution of Pakistan is less than $1 \%$ which is USD 9.6 billion a major source of foreign exchange earnings for the country.

The empirical research plays a very important role in this area of study Bhalhotra (1998, cited in Alam 2011) was the first who investigated the impact of 2008's world financial crisis. Bhalhotra (1998) empirically determined the significant positive effects of capital stock, previous period's employment and output change, and negative effects of man-hours and previous period wages on the employment. Alam (2011), in his research paper concluded that the financial crisis along with many other factors gave rise to the decline of textile industry of Pakistan including; energy crisis, disclosure by textile mills owner, secrecy of information due to tax avoidance all led to the crisis of textile industry. Pimple (2009) in his study on Global financial crisis concluded that, "We must be bold than ever in these times of crisis, when we are tempted to look inward, it is precisely the time when we must move pursuit of the common good to the top of the agenda. While recently we have heard much in the US about how problems on Wall Street are affecting innocent people on Main Street, we need to think more about those people around the world with no streets".

GEC in its study identified two major factors that were hardly hit by the financial crisis; first the developing countries which were having most globally integrated financial sectors next came the impact on trade, as volumes and prices of commodities and manufactures collapsed across the globe. The report also concluded that, "The financial crisis of 2008 has had terrible results in rural areas, firstly unemployment has risen higher and higher as compare to previous crisis, secondly, salaries of people have either dropped or remained same and thirdly, salaries are not available on time to employees as companies are also facing hard time to release cash to employees and they cannot even afford to pay them. The impact of this crisis has been witnessed in healthcare sector as well: for example, one community member who is in need of surgery has had to postpone it because last month her husband's salary didn't arrive. And it is usually the women who are postponing treatment because of the impact of the crisis on household finances. Many women in our community healthcare scheme who have recently undergone mammography screening and been recommended to have surgery now cannot afford to pay for it - this is mostly because of the crisis."

The research on this topic has been very limited and this creates a scarce of literature available on this topic. Other than financial turmoil the political and socio-economic condition of the country is also not favorable this resulted in the continuous bad performance of textile sector although the government subsidies are more as compare to other sectors. Latif et al (2011) in their study showed that the financial crisis is negatively impacting on the trade growth; the exports fell mainly because of a drop in world trade prices. This has also resulted in import of vegetables by the government and now they are working on policy level to smooth out the effect of crisis.

\section{Pakistan Textile Sector and Its Performance:}

Pakistan's textile industry comprises of large scale organized and highly fragmented cottage/medium and small units including; Raw Cotton, Ginning, spinning, Knitting, printing and Dyeing \& Apparels and made ups, these all small industries contribute to make up the overall textile sector. The macro-economic indicators of Pakistan economy shows downward trend since 2007, the pattern as followed by decline in foreign aid, foreign direct investments, and diminishing growth in exports, although there was upward trend of remittances to Pakistan but solely this factor could not contribute for the losses generated by other macro-economic factors. 
Figure 3 Pakistan: Changes in Macroeconomic Indicators

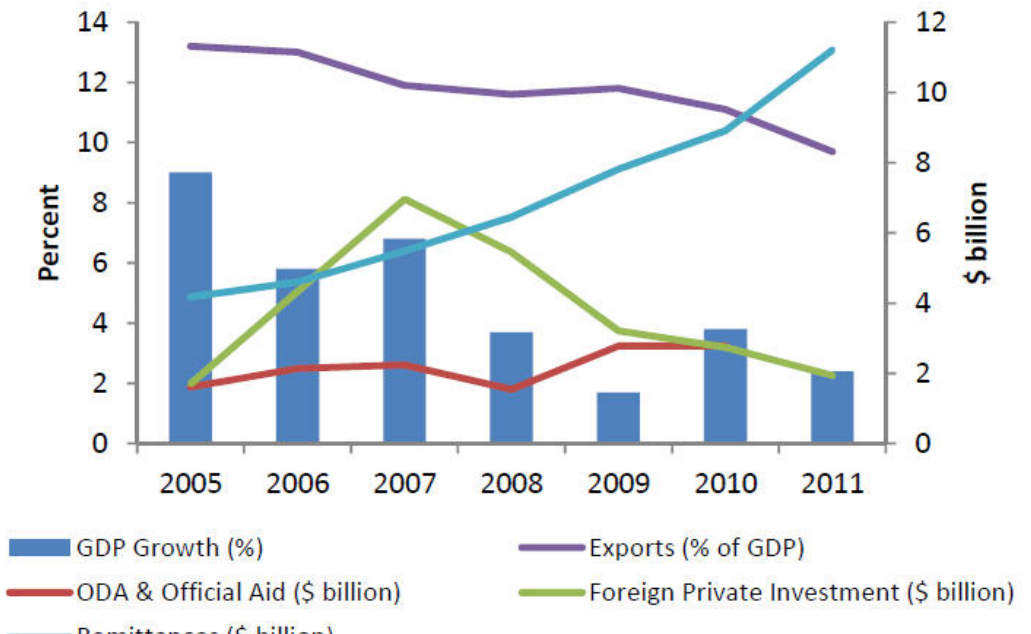

Source: Economic Survey of Pakistan 2010-11

The Economic Survey of 2012 reported that the GDP Growth of the country reported declining trend since 2006, Exports to GDP ratio also declined, foreign official aid and foreign direct investment also showed negative growth whereas Remittances improved and increased. As Alam 2011 discussed in his report that the macroeconomic variables of Pakistan economy are not much hit by the crisis due to low integration of our economy in financial sector. The other factors that were identified in his report included; power deficit in Pakistan, lack of foreign investors, risk awareness together with global financial crisis led to the fall in foreign direct investments. It is therefore concluded in his research that the global financial crisis along with other factors were responsible for the downward trend of textile sector. Now the textile sectors has started performing well and the movement of industries to Bangladesh has led the investor to produce textile products with low cost of production.

\section{Research Methodology:}

Sample:

Purposive sampling techniques is used for the research study, only relevant personnel from the research area on textile sector are contacted and interviewed in order to get the rich information Snowball sampling technique is also used to reach the research participants they were contacted with reference of other people. For this research study 3 interviews were planned to be conducted but due to short of time and unavailability of the participant in Pakistan I was restricted to conduct only 2 interviews. As this is a phenomenology study 2 interviews were done to get the maximum information for our study from the personnel who are working as a research analyst on textile sector of Pakistan as they are aware of the trends and impact of financial crisis on the textile industry.

\section{Research Design:}

The research design that is most suited for this research is Phenomenological research design, as the researcher's main objective is to provide the readers with lived experiences of the experts from the Textile industry of Pakistan during the difficult phase of global financial crisis. In a phenomenology study the researcher transcends or suspects the past knowledge and experience to understand a phenomenon at a deeper level Merleau Ponty, (1956).Exploring the researchers view on textile sector how they look at the crisis and what structural changes they pose in reflection of their work that they were doing during the last 4-5 years. Phenomenological methods are particularly effective at bringing to the fore the experiences and perceptions of individuals from their own perspectives, and therefore at challenging structural or normative assumptions Lester, (1999).

\section{Procedure:}

After the approval and availability from the interviewees the interviews were conducted one person was from the State Bank of Pakistan working in Economic Policy Review Department as Assistant Director since last 04 years, he was working on external sector and had a good knowledge about the textile sector of Pakistan and the global financial crisis. The other interview was conducted online because of unavailability of the interviewer in Karachi; he is Mr. Rao Muhammad Tariq Jahangir, business relations officer at Iqbal Silk Mills, his views were also taken for the data collection purpose. One interview was tape recorded and the other was online both were transcribed verbatim. Participants are established persons in their field and were having useful and rich information on the topic which were posed to them. They cooperated with us even after the interview so that I 
may go back to them and check if the interviews were transcribed properly or not. Whatever I have written was in accordance with what they meant or should I need to make some changes in analysis part.

After informed consent taken from participants they were asked to respond on what they knew about the Global Financial crisis and the textile sector of Pakistan, how they see the whole phenomenon and what measure they pose for improvement of performance of our textile industry. Background information of participants was obtained through the references with the help of whom we reached to our actual research participants.

Data Analysis:

Data collection and analysis in qualitative research are done simultaneously, for this research study researcher I have used Colaizzi's Phenomenological method, to analyze the phenomena and exclude researchers' biases from the research (Groenewald, T 2004). After reading the transcripts various times to have the gist of the whole idea, from each transcript, important phrases and sentences are extracted that most nearly explains the phenomena of crisis in textile sector of Pakistan. The formulated meanings are then divided into themes allowing for the emergence of actual factors that were discussed by both the interviewers. The results are then combined together to develop an in depth and exhaustive description of the phenomenon. Once the data is clustered in themes the research went back to the actual participants to validate the findings, if the data emerged is relevant it is included in the final description and other irrelevant data was excluded from our final report. A mix of data analysis tools are used including IPA and Narrative analysis in order to provide the readers with complete description in the form of narrations of the interviewers and how they make sense out of their experiences are captured and recorded.

\section{Reliability and Validity:}

Methodological severity was attained through the application of verification, validation and validity Meadows \& Morse, (2001). Data reliability and validity in qualitative research is very difficult to identify, for this research study I have used triangulation technique to validate the data collected and analyzed, another way to validate the data is to get back to the participant and discuss again whatever I have analyzed whether the results generated are the same as the participant narrated during the interview or he meant something else and the researcher understood something else. In order to maintain the credibility and trustworthiness of the research the sources from where the data has been collected and the persons interviewed their complete details are provided in the appendices and the transcription of the interviews are also shared. Various sources of data collection have been used to triangulate and validate the results and the findings are in line with the research objective.

\section{Results:}

For the data analysis we have used the transcription following noteworthy statements were extracted, significant statements with their formulated meanings are written in Table 1, while arranging these meanings into clusters 12 themes emerged from data. Table 2 contains the theme clusters that emerged from their associated meanings in connection with the research questions and objectives of the research.

\begin{tabular}{|c|c|}
\hline Statements & Formulated Meanings \\
\hline $\begin{array}{l}\text { As in Pakistan, main hub of textile industry is in } \\
\text { Faisalabad, which was badly effected during last } \\
\text { winter season because of shortage of gas. as a buyer } \\
\text { we have to pay full payment in advance for the } \\
\text { delivery and the quantity we order wouldn't be } \\
\text { fulfilled, quality is sacrificed and time also. } \\
\text { some of them shifted to abroad because of bribe } \\
\text { demand, one more thing is, some business man shifted } \\
\text { to rural areas of Karachi } \\
\text { The Financial crisis did impact the textile sector but } \\
\text { the impact was not very severe if we compare it with } \\
\text { other countries, the point is that Pakistan exports low } \\
\text { value added products like raw cotton, cotton yarn and } \\
\text { cotton fiber these are low value added products. } \\
\text { whatever the demand is these kind of products raw } \\
\text { cotton, cotton yarn there demand will always be there, } \\
\text { the point is that textile exports did slow down but not } \\
\text { very significant } \\
\text { as large scale manufacturers have there own } \\
\text { powerplants to electricity generation. }\end{array}$ & $\begin{array}{l}\text { Energy shortage is one of the main cause of crisis of } \\
\text { textile sector in Pakistan, mill owners are unable to } \\
\text { complete the project on time and could not deliver the } \\
\text { finished goods on time as well } \\
\text { Small and medium manufacturers move to Bangladesh } \\
\text { for low cost of production facility and high profit } \\
\text { margins } \\
\text { As Pakistan is low value products making company } \\
\text { therefore the financial crisis impact on it is very low as } \\
\text { compare to high value products making countries } \\
\text { The demand for low value products i.e. raw cotton, } \\
\text { cotton yarn and cotton fiber will always remain there } \\
\text { as high value products making countries will require } \\
\text { them. } \\
\text { The manufacturers e.g., Gul Ahmed, Al Karam and } \\
\text { Nishat they have their own power Plants therefore they } \\
\text { faced little or no disturbance from energy crisis. } \\
\text { It was difficult for small and medium manufacturers to } \\
\text { survive in energy shortages so they decided to move as } \\
\text { they were producing gloves sox etc so their market }\end{array}$ \\
\hline
\end{tabular}


The medium and small size manufacturers who are operating in two rooms' factory producing gloves sox etc export they have their markets and faced an impact on main exports. So the decided to switch to

Bangladesh took their unit their and collaborated with local manufactures.

Two aspects are there first the shortage of electricity and cost of production in Bangladesh is very low and

$2^{\text {nd }}$ is that Bangladesh enjoys additional benefits from EU generalized store preference, also available to Pakistan but Bangladesh can export in extra Quantum, so if an investor wants to exports finished goods he can export more from Bangladesh and in good rates 100 gloves from 200 gloves can be exported The other major reason is that India does not want to export directly in Pakistan, so they could invest in Bangladesh Company and avoid political pressure as well.

The third aspect is that China, India and Bangladesh is our major competitors in Raw cotton, but production of raw cotton is better than these countries, this is our competitive advantages as well and we export Raw cotton to China and Bangladesh so our mill owners decided that if we are exporting raw cotton to Bangladesh it is much better we should move there and export high value product to worldwide. was getting disturbed.

One major reason for shifting of factories to

Bangladesh is that cost of production is low there and the mill owners does not have to setup an additional plant their and maintain the facility but they work in partnership with ocal manufacturers and share their factory premises for their production of finished goods and are earning ample profits.

Bangladesh enjoys additional benefits from US and EU in terms of exports they are allowed to export in more quantities as compare to other companies so our investors are enjoying that benefit also

Indian investors are not allowed to make their investments directly in Pakistan, so by moving to Bangladesh Indian investors can also invest in our companies and help us in earning foreign exchange in ample quantities

One major benefit that we enjoy is that the production of cotton is more than our requirements so we can export raw cotton in more quantity to Bangladesh and increased our production of finished goods and enter the International Market via Bangladesh.

\section{Table 2: Example of Cluster Themes with their formulated Meanings:}

Manufacturer or Low Value Products:

- Exporter of Raw Cotton, Cotton Yarn and Cotton Fiber

- Exporting raw cotton to our competitor countries

- Low cost benefit in Bangladesh

- Lack of technical facilities

\section{Domestic Issues:}

- $\quad$ Energy Crisis

- Law and Order Situation of the Country

- Internal Instability

- Reluctance of Foreign investors

- Small and Medium investors movement to Bangladesh

- Unable to complete assignments on time 
The financial crisis of 2008 did impact the Pakistan textile sector but its impact was very low as compare with other countries, Pakistan's major exports are from low value added products like raw cotton, cotton yarn and cotton fiber. The high value products are readymade garments, bed ware, towels which we do not export to USA and EU in high quantity. When the global financial crisis was on its peak Pakistan exports bit slow down but its impact was not severe, as whatever the demand is these kind of products raw cotton, cotton yarn and cotton fiber there demand will always remain same, our textile did slow down but not very significantly. As compare with China, India and Bangladesh because they export high value products like readymade garments, jackets, denim etc. products, so this was the main thing that it did impact and our exports went down. But financial crisis was an important factor which led to the overall slowdown but this was not the only factor domestic factors are also there. If we start producing high value products and export them directly to US and EU then our market will be expanded but currently we are supplying raw cotton to our competitors only.

\section{Theme 2: Movement of Small and Medium Manufacturers:}

Small and medium manufacturers are the one which were most affected by the textile sector bad performance, small manufacturers operate in a two room factory, manufacturing gloves and sox etc they have their own market for exports, they were highly affected when the financial crisis took place and simultaneously the energy crisis. Energy shortages were the main cause that they decided to move to Bangladesh as they were unable to complete consignments on time and lost their potential customers. The investors also preferred to give projects to a country where internal stability and energy crisis are not there and they expect the consignment to reach them on time. Therefore the small and medium manufacturers shifted their setup to Bangladesh so that they may have low cost of production and complete their work on time. These manufacturers in collaboration with local textile investors signed deal to use their premises for work and share the profit.

\section{Theme 3: Increased Profits:}

The movement of small and medium manufacturers led them to work efficiently and have higher returns on their investment abroad. Bangladesh is a good place to work for these investors they face less legal proceedings there and have benefit of producing at low cost without heavy investment of installation of plant and machinery and its maintenance, they simply share the factory of local manufacturer and export them raw cotton and earn huge margins of profit and sent them back to Pakistan. Another aspect of this is that the Indian investors were not allowed to make their investments directly in Pakistan so they also have the benefit to make their investment in Pakistani company while staying in Bangladesh without any political pressure. The other major benefit of working in Bangladesh is that they enjoy additional benefits from US and EU generalized store preference, also available to Pakistan but Bangladesh can export in extra Quantum, so if an investor wants to exports finished goods he can export more from Bangladesh and in good rates 100 gloves from 200 gloves can be exported. In this way more exports of finished goods are possible for the manufacturers of Pakistan as well.

\section{Theme 4: Ample Production of Raw Cotton:}

Pakistan's fertile land is very favorable for the production of cotton, our yearly production is more than our requirement therefore it becomes easy for us to export raw cotton. Before the textile industry crisis, if the production of cotton was 100 bales we used to export 50 bales and the remaining 50 bales were used internally for the production of high value products and the demand of local citizens were met. But now if the production is 100 bales we export 80 bales and use 20 bales to cater internal demand currently we are not exporting any high value products in international market. Other dynamics for China, India, Bangladesh and Pakistan are same but one additional benefit we ought is the excess production of raw cotton. Pakistan is now exporting raw cotton to regional countries who are our close competitor also and they purchase cotton in low prices from us and refine them and produce high value products and export to US and EU.

\section{Theme 5: Energy Crisis:}

The major reason for the Textile industry crisis is the energy shortages throughout the country our entire textile mills are closed in Faisalabad due to no electricity. There are two issues in this, first that large scale textile mills does not faced any problem in energy crisis but the impact was on low scale manufacturers as large scale manufacturers have there own powerplants for electricity generation. The medium and small size manufacturers who are operating in two rooms' factory producing gloves and sox etc. export they have their markets and faced an impact on main exports. So the decided to switch to Bangladesh took their unit their and collaborated with local manufactures. The problem of energy crisis started in 2008 when global financial crisis was at its peak and now when the financial crisis in US and EU has slow down the energy crisis in Pakistan is at its peak, therefore we cannot say that the major reason for the downward trend of our textile industry is due to the global financial crisis.

Theme 6: Internal Instability:

Pakistan is facing internal instability during the last few years, terrorist activities are all time high, law and order situation is also not good, call for strike and lockout may take place anytime. Uncertainty is everywhere no one is sure of their life, in such a turmoil situation foreign investors are also reluctant to come to Pakistan and make 
their investments here because they believe if they come here and before reaching to Faisalabad, to see their production status, they will be killed in a bomb blast or something will happen to them. The other problems include unemployment increased, in Faisalabad where the workers earlier work in double shifts are now working in single shift because there is no electricity available for them to work. Shortage of energy is one of the most significant problems which everyone in our country is facing. First we need to improve our internal problems and show to world a soft image of Pakistan so that new investors may come in and make their investments in Pakistan.

\section{Theme 7: Activities of Large Manufacturers:}

The large manufactures are producing their own electricity from power plants they have installed at their premises they would not allow small and medium investors to share their electricity. Either the geographical boundaries will come in between i.e. a factories at Chenab will not be able to share electricity with a power plant in Sind. Small investor will not be allowed to work in the factory premises of the large manufacturers as they will copy their prints, design and technology. Therefore small and medium manufacturers are moving to Bangladesh because they are having low cost of production and cheap labor.

The large manufacturers for example Gul Ahmed, Nishat Mills, Al-Karam has shifted their concentration from exporting finished products to serving needs of local market, as designers lawn prints are more in fashion these days so they are earning good profits from their domestic market only. A small share of unstitched suits are exported to India informally through participating in trade exhibitions, seminars and fashion shows, whereas they are not involved in direct exports to India and other countries. The revenue earned from this activity is not part of exports of our country but are included in services industry revenue. Scope and marketing activities are very active for these companies but for the time being their primary focus is domestic market however there is immense demand for our lawn products in international market.

The prices of the local manufacturers are high due to competition, the consciousness among customers about fashion trends, even fashion models have started to launch their own lawn prints. The market to which they are catering is very limited and high class, so they can afford to pay for such high prices; these companies are getting good profits from their domestic market only. The focus of this trend is in urban areas only their market is very limited and the people are ready to purchase these products at high prices as well.

\section{Theme 8: Movement of Labor:}

Unemployment has increased in Pakistan, as our labor is unemployed, earlier they were working in double shifts now single shift is hardly available. This is the reason why our labor is moving to Middle East and Bangladesh, for the work. as they believe that there are work opportunities for them and they can earn good and sent money back to their families. In order to retain our skilled labor we need to improve the performance of our textile sector by creating a conducive environment for work, improved law and order situation, reduced energy shortages etc.

\section{Theme 9: Outsourcing Textile Segment:}

Outsource activities which US and EU used to do in recent times was very limited in our market, and now that segment is also facing energy shortages this is why their work is disturbed and this segment is highly affected by the financial crisis, overall in our textile sector the contribution of this segment is very low i.e. 5 to $6 \%$ only therefore the disturbance in this segment does not contribute much in the crisis of our textile sector. Simultaneously the cotton prices went up and the export proceeds from raw cotton led us to cover the loss which we suffered in outsource activities segment.

\section{Theme 10: Reluctance of Foreign Investors:}

One of the major drawback of our country is that the perception of Pakistan is not good in the eyes of the world, foreign investors believe that if they will come to Pakistan they will be killed in a terrorist activity, therefore they also prefer moving to Bangladesh, India and China because they found economic, political and social stability in these countries. The World Economic Forum report states that Pakistan is the $2^{\text {nd }}$ worst country in terms of stability, after reading such reports who will come to Pakistan for investment. We need to improve our image by marketing soft image of Pakistan to the world.

\section{Theme 11: Marketing Strategies of Our Textile Companies:}

In order to improve our textile sector performance we need to focus on marketing strategies for the textile i.e. participation in trade exhibitions, seminars, fashion shows etc. all around the world so that a soft image of Pakistan may appear in front of them as our competitor countries are doing. Textile sector must focus on introducing their brands in international market and increase marketing activities. Explore new markets like South Africa, Middle East and other countries where we find potential customers so that our export of finished goods may increase and help us in gaining more profits and export receipts.

\section{Theme 12: Other Domestic Issues:}

Other than Energy crisis there are various other domestic issues which we must cater to improve our performance of textile sector i.e. law and order situation of the country, political stability, corporate governance practices of textile sector companies and the regulatory bodies, accountability of manufacturers and investors 
and the improvements in the structural flaws of the textile sector. If we cater the domestic issues first then ultimately our performance would improve in front of the whole world and our textile industry would be recognized among them.

\section{Discussion:}

In this study, implications of global financial crisis on textile sector of Pakistan, the reasons which were identified other than financial crisis are energy shortages, law and order situation of the country, internal instability, interests of small and medium manufacturers, all these factor led to the development of crisis of our textile sector. The practice of exporting raw cotton to our competitor countries has allowed Pakistan to reduce its production of finished goods to cater the demand of domestic customers only where as if we export raw cotton in less quantity we can increase the production of finished goods and earn export proceeds from US, EU and other African and Middle East countries. This is one of the major structural flaws in the textile industry of Pakistan. The bodies which are working for the textile companies include; Pakistan Textile Exporters Association (PTEA), All Pakistan Textile Mills Association (APTMA), and Ministry of Textile all together needs to make some structural changes in textile sector in order to improve its efficiency and effectiveness.

The one major drawback of Pakistan textile industry is that we export low value products to our competitor countries in good rates and they refine the cotton and produce high value products and earn far more income from exports, this structural flaw can be mitigated by reducing the exports of raw cotton and increased export of high value or finished goods. Along with this marketing strategy should also be improved so that we can market soft image of Pakistan by sharing our culture and attitude in the international market and once again we'll be able to increase our exports in international market. All this can be done once energy crisis problem is resolved the major concern for manufacturers today is the shortage of energy, textile mills rather than moving to Bangladesh, they together with the help of Government of Pakistan, can make a one time investment of Power plant which can produce electricity for the mills only in this way our industry will remain in our country and the production efficiency would improve.

In order to attract foreign investors to Pakistan, the Government should stabilize the law and order situation so that the life of every citizen is secured and the foreign investors would come to Pakistan with confidence. If FDI will come to Pakistan we will be able to export directly to US, EU and other parts of the world and earn more revenue from exports rather than from remittances or in any other form. The textile sector of Pakistan has every potential to work efficiently but this short term energy crisis has disturbed our performance. the investors who have already moved to Bangladesh are not likely to return in 10 to 20 years because they have made their investments there and even they have not yet achieved their break even, so they must continue working there and simultaneously earning from there they must invest in Pakistan so that one source of investment in textile sector will be from there contribution it will help us in stabilizing and improving the overall performance of the textile industry of Pakistan. The link of crisis of Pakistan textile industry and global financial crisis is very thin, beacsue when the financial crisis was at its peak in 2008 the textile sector performance was hardly affcetd and now when the financial crisis has been slow down our textile sector performance has worsen. Therefore we conclude that there is not direct link between textile sector of Pakistan and the global financial crisis however unlike other countries of the world in some sectors we have also faced some recursions of crisis but there is no direct link found in the financial crisis and textile sector crisis of Pakistan.

\section{References:}

Abbas et al 2012, "Impact of Financial Crisis on Textile Industry in Pakistan", Information Management and Business Review, Vol. 4, No. 7, pp. 409-416

Ahmed A, 2011, "Growth Trends of Pakistan Textile Industry", < http://www.rcci.org.pk/wpcontent/uploads/2012/12/gtopti.pdf>

Ahmed, Y, 2008, “Textile Industry of Pakistan”, Horizon Securities

Alam I, 2011, Impact of Financial Crisis on Textile Industry of Pakistan: Evidence from Faisalabad, South Asia Network of Economic Research Institutes, No. 11-12

Chhibber, J, Ghosh, J, Palanivel, T 2009, "The Global Financial Crisis and the Asia-Pacific region, A Synthesis Study Incorporating Evidence from Country Case Studies"

Forstater, M 2007, "Implications of the global financial and economic crisis on the textile and clothing sector", International Labour Organization, Sectoral Activities Programme

Green, D, King, R, Dawkins, M 2010, “The Global Economic Crisis and Developing Countries: Impact and Response", Oxfam Research Report

Groenewald, T 2004, “A phenomenological research design illustrated', International Journal of Qualitative Methods, vol. 3 no.1. Article 4 viewed February 11, 2013 from <http://www.ualberta.ca/ iiqm/backissues/3_1/pdf/groenewald.pdf>

Iqbal et al, 2010, “Development of Textile Industrial Clusters in Pakistan”, Asian Social Science, Vol. 6, No. 11 
Memon, A 2012, "Pakistan ranks as one of the major woven fabrics suppliers", viewed February 10, 2013 : <http://www.ptj.com.pk/Web-2012/06-2012/Weaving-DrNoor-Ahmed.htm>

PACRA 2012, "Textile Sector Study", The Pakistan Credit Rating Agency Limited, < http://www.pacra.com.pk/pages/research/archive/sector_study/textile/Study/Textile_SS_Dec_12.pdf>

Tahir, M, Mughal, K 2012, "Pakistan Textile Industry and The Neighbouring Countries (A Globalization Effect)", Far East Journal of Psychology and Business, Vol. 8, no. 2, pp 66-70

Usmani F, 2012, “Textile Industry of Pakistan”, Viewed February 10, 2013 http://www.utrade.co/Magazine/Utrade-Magazine.aspx?Key=392\&Title=Textile+Industry+of+Pakistan

Pakistan Textile Export Association, Viewed on April 05, 2013, < http://www.ptea.org.pk/>
Ministry
of
Textile,
Viewed
on April
12 ,

2013

http://www.textile.gov.pk/gop/index.php?q=aHR0cDovLzE5Mi4xNjguNzAuMTM2L21vdGkv>

All Pakistan Textile Mill Association, Viewd on March 25, 2013, < http://www.aptpma.com/>

Pakistan Textile Journal, Viewed on March 20, 2013<http://www.ptj.com.pk/> 
The IISTE is a pioneer in the Open-Access hosting service and academic event management. The aim of the firm is Accelerating Global Knowledge Sharing.

More information about the firm can be found on the homepage:

http://www.iiste.org

\section{CALL FOR JOURNAL PAPERS}

There are more than 30 peer-reviewed academic journals hosted under the hosting platform.

Prospective authors of journals can find the submission instruction on the following page: http://www.iiste.org/journals/ All the journals articles are available online to the readers all over the world without financial, legal, or technical barriers other than those inseparable from gaining access to the internet itself. Paper version of the journals is also available upon request of readers and authors.

\section{MORE RESOURCES}

Book publication information: http://www.iiste.org/book/

\section{IISTE Knowledge Sharing Partners}

EBSCO, Index Copernicus, Ulrich's Periodicals Directory, JournalTOCS, PKP Open Archives Harvester, Bielefeld Academic Search Engine, Elektronische Zeitschriftenbibliothek EZB, Open J-Gate, OCLC WorldCat, Universe Digtial Library, NewJour, Google Scholar

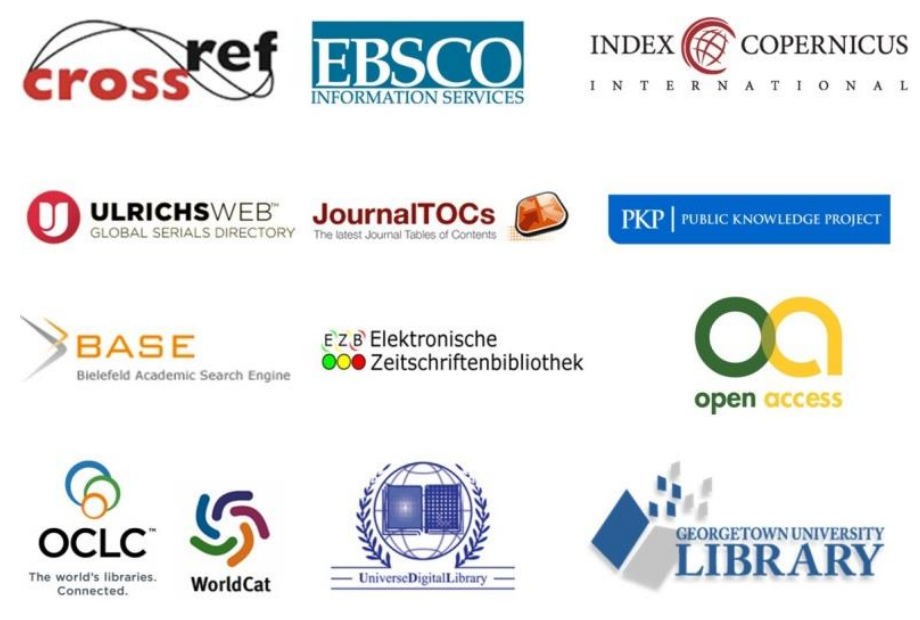

